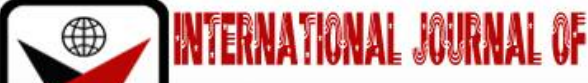 \\ X
}

ISSN 2278-0211 (Online)

\section{Resilient Distribution Networks for Disaster Relief to Internally Displaced People's Camps in North Eastern Part of Nigeria}

\begin{tabular}{c} 
Oke, Joseph Adewale \\
Lecturer, Department of Purchasing \& Supply, \\
Adeseun Ogundoyin Polytechnic, Eruwa, Nigeria \\
Odeyemi, Tosin John \\
Lecturer, Department of Business Administration, \\
Adeseun Ogundoyin Polytechnic, Eruwa, Nigeria \\
Carim, Abiola Abass \\
Lecturer, Department of Marketing, \\
Adeseun Ogundoyin Polytechnic, Eruwa, Nigeria \\
Alabi, John Adejare \\
Lecturer, Department of Marketing, \\
Adeseun Ogundoyin Polytechnic, Eruwa, Nigeria \\
Abdulkareem, Kehinde Ronke \\
Lecturer, Department of Business Administration, \\
Adeseun Ogundoyin Polytechnic, Eruwa, Nigeria \\
\hline
\end{tabular}

\begin{abstract}
:
Humanitarian operations rely extensively on logistics, particularly in uncertain, risky and urgent circumstances. Over the last two decades, disasters have caused significant loss of human life and economic loss. In Nigeria, insurgence as a form of man-made disaster has caused a lot of humanitarian crisis so far experienced in the nation, such as human casualties, forced displacement, refugee debacles, food insecurity and the spread of various diseases. The problems encountered by the Internally Displaced People (IDP) with regards to delivery of relief materials is an indication that the various measures put in place by the government are far from meeting the needs of the IDP in their various camps. This paper examines the distribution network of the relief materials, relying on information from secondary sources and recommends the need for an enabling law to be guiding the activities of the agencies involved in the distribution process, by signing National Disaster Management Framework (NDMF) into law, the use of $3^{\text {rd }}$ Party Logistics (3PL) in the distribution network to minimize corruption and the bureaucracy involved in using government agencies as it is, presently.
\end{abstract}

Keywords: Distribution network, resilience, disaster relief, internally displaced people

\section{Introduction}

Humanitarian supply chains involve the efficient flow of relief materials to the victims of a disaster. It entails the activities of various organizations such as international aid agencies, governmental and non-governmental aid agencies, to provide basic human needs such as shelter, food and water to victims of a disaster. The supply chain must be efficiently managed, to avoid break down at the receiving end (Munslow, 1999:207-221; Byman, Lesser, Pirnie, Benard, \& Waxman, 2000:23). Humanitarian organizations supply goods and services to people in need, using funds provided by donors that are supporting their mission (Burkart, Besiou \& Wakolbinger, 2016:31)). This type of supply chain is characterized by unstable political donations from governments as well as rivalry among the humanitarian organizations in the private sector. Donations from government may be delayed due to administrative bottlenecks. As in the case of Japan's disaster of 2011, Kyoto news reported that the failure of Japan disaster management was due to lack of good political leadership, delayed response of the government to the disaster, constraints in military and inefficient communication systems (Mat Daud, Hussein, Nasir, Abdullah, Kassim, Suliman \& Saludin 2016:109).

\section{Objective of the Research}

This study seeks to examine the distribution network of disaster relief materials for Internally Displaced People in Nigeria, to explore the factors responsible for its effectiveness or otherwise, with the aim of giving possible 
recommendations that could enhance its effectiveness.

\section{Methodology}

The study, as a qualitative research gathered all its information from available, but reliable secondary sources for the purpose of achieving the objectives of this research work.

\section{Humanitarian Logistics versus Business Logistics}

Humanitarian logistics is similar to business logistics in that it deals with the effective and efficient flow of goods and information from the point of origin to the point of consumption (Abushaikha \& Schumann-Bolche, 2016191). The use of third-party logistics provider (3PL) is a common practice in business logistics. Similarly, the emergence of Humanitarian Logistics Service Providers (HLSP), such as United Nations Humanitarian Response Deport (UNHRD), the Regional Logistics Units (RLUs) and the Humanitarian Procurement Centers (HPCs) has helped to improve the coordination of efforts of relief actors (Dufour, Laporte, Paquette and Rancourt 2018:1). Business logistics is 15 years ahead of humanitarian logistics, the later has being in operation 15 years earlier than the former (Ertem, Buyurgan\& Rossetti, 2010:204; Bag, 2016:175). Nogueira, Goncalves and Novaes (2008:3) stressed that conditions faced by firms are different from those faced by organizations or societies in disaster. There are specific characteristics of humanitarian logistics that differ from traditional business approach, such as issues relating to human life, unreliable or non-existence of information which make it difficult to identify those who are in need of relief materials, what they actually need and the quantity needed. Based on these characteristics, demand is generated by random and unpredictable effects.

\section{The Devastating Effects of Insurgence by Boko Haram Terrorist Group in Nigeria}

The insurgence of Boko Haram terrorist group in Nigeria which began in 2009 has had a devastating effect on the people in the North Eastern part of Nigeria, especially in the Borno, Yobe and Adamawa states. The impact of Boko Haram insurgency in a broad sense covers Bauchi, Borno, Yobe, Adamawa, Gombe and Taraba states, all in north-eastern part of Nigeria (Dunn 2018:3). While Borno, Yobe and Adamawa states are described as conflict affected states because of the direct impact of the insurgency on them, Bauchi, Gombe and Taraba states are referred to as non-conflict states, since the insurgency has indirect impact on them (Dunn 2018:4). Hence, the basis for concentrating on Borno, Yobe and Adamawa states for this research work.

Moreover, it is estimated that about 6.9million people require humanitarian health services in the north-eastern region of Nigeria, including more than 1.7million IDPs in about 100 IDP camps in the conflict affected area earlier discussed (Gamawa 2017:40). Although these are not permanent camps, but there is likely tendency that they will continue to exist as the conflict is still on-going (Fineman 2018:117).

In Nigeria, fight against the insurgence which has claimed tens of thousands of lives and displaced millions of people remains one of the nation's deadliest conflicts (Campbell \& Harwood 2018:1). The United Nations' Refugee Agency (2017) estimated that the conflict with Boko Haram has displaced 1.7 million people and also put more than seven million people at the risk of starvation in Adamawa Borno and Yobe states. About 6.9 million were in need of humanitarian health services, while 4.6 million were affected by food insecurity in the entire north-eastern region.

\section{An Evaluation of Disaster Risk Mitigating Strategy in Nigeria}

Creation of Internally Displaced Persons' Camps (IDP camps) since the conflict started in 2009 till date was a coping strategy adopted by Nigerian Government to alleviate the multi-faced problems of the IDPs in the conflict affected area(Olanrewaju; Omotosho \& Alabi 2018:152). Although, IDP camps are not meant to be permanent in nature like refugee camps, the fact is that they cannot be closed in a short period to this time, because the conflict is on-going (Fineman 2018:117).

Moreover, the National Disaster Management Framework (NDMF) of 2010 was formulated to provide a mechanism that serves as a regulatory guideline for effective and efficient disaster management in Nigeria. The objective of NDMF was to establish functional disaster management institutions at all levels of government to prepare for, prevent, mitigate, respond to and recover from disasters in Nigeria (NEMA 2010). This gave operational guidelines to National Emergency Management Agency (NEMA), State Emergency Management Agency (SEMA) and Local Emergency Management Agency (LEMA), in performing various duties. Another objective of NDMF was to develop the capacity of relevant institutions and stakeholders for effective and efficient disaster management in Nigeria. It should be noted that the NDMF has not received legislative backing since its inception in 2010 (Okoli 2014:39). Therefore, until it is signed into law, the document still remains a mere guideline and not a legal framework. This poses a great challenge to NEMA in carrying out its disaster management responsibilities in Nigeria (Okoli 2014:39).

However, the Nigerian NDMF is similar to South African National Disaster Management Framework of 2005. The policy framework seems to be working effectively in South Africa, especially in the management of 2018 drought in Western Cape, the Alex fire outbreak of 2019, where about 1500 people were affected and 500 homes were destroyed, the fire outbreak of Chicago in Paarl East where 400 people were rendered homeless, to mention few(Gift of the Givers Foundation, South Africa 2017, 2018 and 2019). With regards to the 2018 drought in Western Cape, there was scarcity of drinking water in the province; therefore, the Western Cape Provincial Disaster Management Department contacted nongovernmental organizations to urgently assist the province with donations of bottled water to alleviate the problem (Gift of the Givers Foundation, South Africa, 2018).

NEMA, as an institution, set up to meet international and regional obligations of taking care of the IDP in Nigeria has failed in performing its statutory responsibility, although, the agency also attributed its failure to lack of adequate 
funding by the Federal Government (Adewale, 2016:187).Imasuen (2015:291)maintained that there was lack of humanitarian law and policy framework in Nigeria to clearly define roles and responsibilities of humanitarian actors, which eventually hindered effective coordination of various humanitarian efforts. This is an indication that NDMF and all its provisions only appear on paper, but are not operational, despite the fact that Nigeria is a signatory to Geneva Convention of 1949. Moreover, monitoring and evaluation of effectiveness of humanitarian assistance is weak and requires significant improvement, as some of the humanitarian actors seem not to have internal mechanism to monitor assistance and protection interventions (ICRC, 2016:8). Not only that, the IDP are not properly involved in the decision process of how to address their needs, hence, the possibility of the relief efforts not really meeting their various needs (ICRC 2016:8). A survey conducted by ICRC indicated that only 23\% of the IDPs had been able to participate in decisions about how to address their protection and assistance needs (ICRC, 2016:8). Furthermore, there is lack of systematic data collection, which makes it difficult to estimate the number of people in need and their actual needs (Ismasuen, 2015:291). For disaster response, estimating the demand for relief materials relies majorly on secondary data collected from relevant government agencies, as there may not be direct access to primary data in the crisis affected area. There is need to facilitate the roles of the humanitarian actors, by ensuring timely and simplified procedures for importing humanitarian relief items, to ease the problem of delay in delivery of relief materials (ICRC, 2016:12).

There is need for proper implementation of the operational guidelines of NDMF in Nigeria, especially in the affected region. Moreover, the activities of the various governmental organizations like NEMA, SEMA and LEMA, and other relevant institutions and stakeholders must be properly channeled towards building a more resilient distribution network for relief materials to various IDP camps.

As provided by NDMF operational guidelines, NEMA is responsible for mobilizing financial resources and also collecting relief materials from all non-governmental and international aid agencies for distribution to disasters victims. There is a need to recommend a unique humanitarian logistics model to Nigeria and also recommend the full implementation of the provisions of Geneva Convention of 1949 in disaster management in Nigeria.

\section{Analyzing the Challenges Confronted by Humanitarian Logistics in Nigeria}

According to International Committee of Red Cross- ((ICRC 2016:40), the relief materials from the Federal and State Governments were delivered to the IDP through State Emergency Management Agency (SEMA) and Federal Emergency Management Agency (NEMA). The United Nations Food Programme (UNFP) also supported 95,000 IDPs with cash-based transfers, 153,000 IDPs with food assistance and 99,130 IDP children with specialized nutritional support, just like many other organizations, such as International Organization for Migration (IOM), The United Nations Refugee Agency (UNHCR), International Rescue Committee (IRC) and Norwegian Refugee Council (NRC) also provided relief materials to the IDPs. (ICRC 2016:40\&41).

However, despite all these efforts, the needs of IDPs in the various camps still remain high (ICRC 2016:16).Many IDP in the IDP camps found it difficult to access adequate food, shelter and safe drinking water, apart from other challenges like lack of adequate care, absence of freedom, financial lack, poor education and family disintegration (Okwute, Sanda and Usman 2017:210).According to Thomas and Kopczak(2005:5) as well as Rolando and Van Wassenhove (2008:550) organizations that are involved in the positioning and supply of equipment and personnel during and after disasters are confronted with serious logistics challenges. Natural disasters require immediate response, as delay may lead to loss of lives. Adequate information is essential for proper assessment of the extent of a disaster and the needs of its victims.

Moreover, the humanitarian logistics is characterized by irregular demands, as disasters, especially the current insurgence are unpredictable and there is no estimation of the volume of aid that will be demanded. Therefore, the use of Information Technology (IT) tends to enhance the resilience of the humanitarian supply chain (Fritz Institute, 2005:12). For instance, the use of an IT-enabled relief network model for a more accurate demand forecasting can enhance effective disaster management and recovery. Developing flexible technology solutions will improve responsiveness by creating visibility of materials, pipeline and increasing the effectiveness of people and process, while advanced information systems will create the infrastructure for knowledge management, performance measurement and learning (Fritz Institute, 2005:12). The development of Information Technology (IT), such as Radio Frequency Identification (RFID) helps to combine the various information technologies, such as database management system, computer network, firewall, etc., to provide an automatic, secure, and convenient real-time control system (Lin, 2009:833). Accuracy and timeliness are two main concerns in the operation process control of supply chain management; therefore, RFID technology can support realtime control of goods in the supply chain including raw material, work in process (WIP), and finished product. It can enhance the degree of automation, reduce the probability of error, and greatly improve the visibility in the supply chain (Lin, 2009:833). For humanitarian organizations to cope with both abnormal and normal risks so as to avoid disruptions in the supply chain, there is need for effective humanitarian risk mitigation strategies (Marianne, 2017:86-88). Therefore, to ensure supply chain resilience, Chopra and Sodhi (2004:53-61) suggested that humanitarian supply chains should have a 'flexible supply base,' that can easily adjust to changes in demand for relief materials and 'strategic stocks', which maintain certain quantities of the relief materials to meet unexpected demand, as effective strategies that tend to mitigate disruption.

The figure 1 below shows the present distribution network of relief materials in Nigeria. 


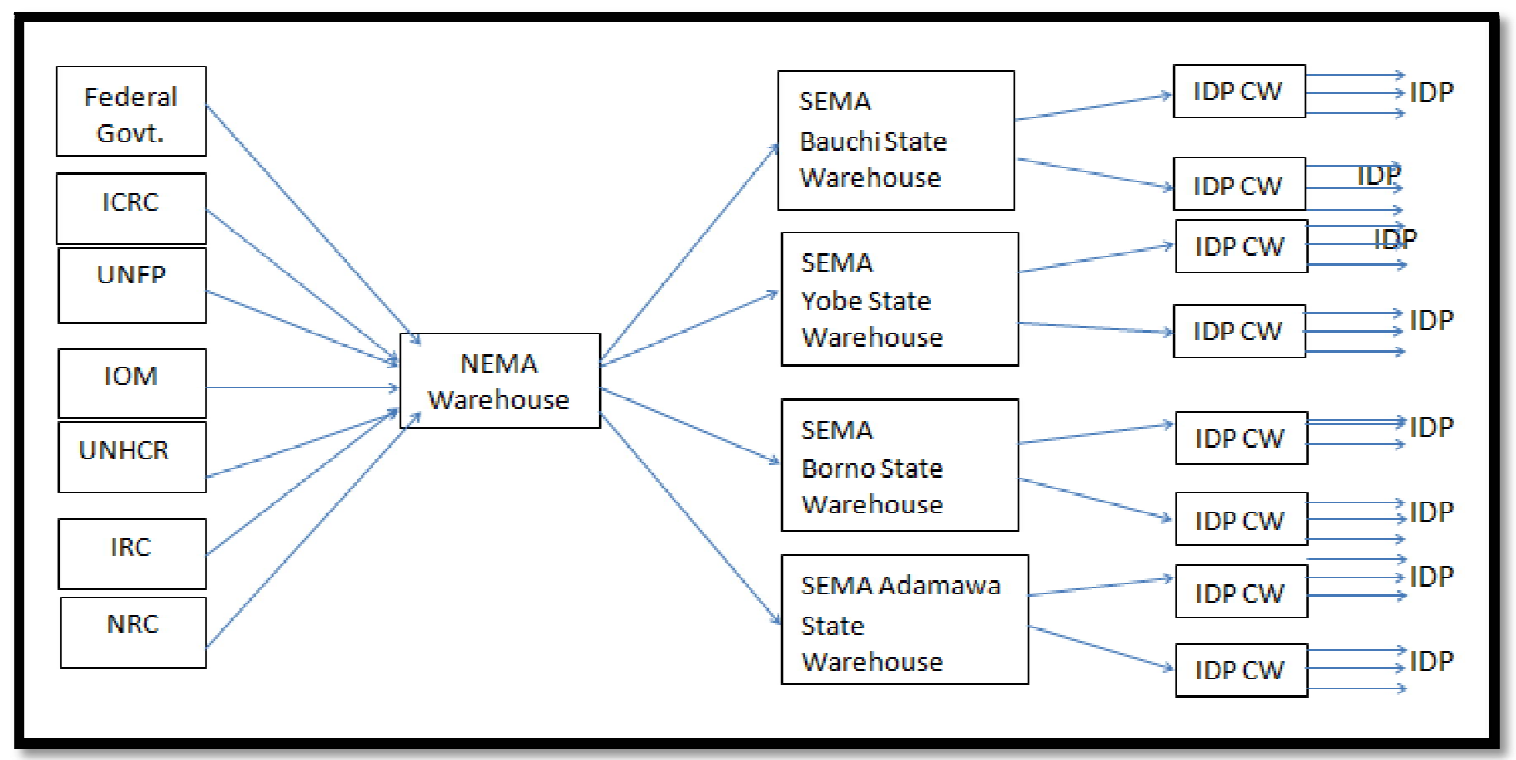

Figure 1: As-Is Distribution Network of Relief Materials in Nigeria

Source: Designed by the Authors

\section{The Use of Mathematical Models in Facility Location and Network Design for Distribution of relief Materials}

There are great number of complicated mathematical models and solution methods that could be employed to solve relief logistics problem, with the requirement that all factors involved (in each model) must be known exactly (Bozorgi-Amiri; Jabalameli; Alinaghian \& Heydari 2012:358). Therefore, uncertainties concerning demand, locationdistance, travel-time and suppliers are not taken into consideration.

For designing Humanitarian Relief Chains (HRCs), optimization-based decision models could provide timely and effective solutions for the decision makers, but analytical methods and optimization-based mathematical models concerning the logistical problems in HRCs under mixed uncertainty are scarce in the literature (Tofighi; Torabi \& Mansouri 2016:241). Tofighi et al (2016:241) further maintained that despite the fact that uncertainty is one of the characteristics of humanitarian supply chain, there are limited works dealing with this issue, while most of them are based on stochastic programming approaches.

Therefore, Tofighi et al (2016:249) proposed a two-stage scenario-based Probabilistic-Stochastic Programming (SBPSB) approach, which addresses a two-echelon humanitarian logistics network design problem, involving multiple central warehouses CWs) and local distribution centers (LDCs). The model suggests the establishing of LDCs and CWs, specifically two CWs with medium capacity and the rest (LDCs) at the minimum capacity. According to Tofighi et al (2016:249), SBPSB as a model was applied to the design of relief network in Tehran, and the superiority of its resulting solution when compared with existing networks reveals its robustness.

However, the gap is that the model does not consider capacity constraints on transportation routes, as well as suitable inventory control policies for perishable relief items and the possibility of local transshipment between various LDCs to decrease the unmet demands (Tofighi et al 2016:249). All these limitations can be taken care of by Logistics Service Providers (LSPs). This shall be discussed here after.

\section{The Use of Logistics Service Providers (LSPs) in Humanitarian Logistics}

Known is the fact that humanitarian operations rely so much on logistics support and supply chain management (Blecken 2010:688). Recent research works shows that Logistics Service Providers (LSPs) have become important players in the humanitarian field by providing support to NGOs and government when they respond to disasters, as part of their Corporate Social Responsibility (CSR) (Diego and Christine 2015:352). Although, logistics outsourcing is widespread and there are more and more natural disasters requiring higher logistics capabilities, the humanitarian literature pays little attention to the roles LSPs could play in this context (Diego and Christine 2015:362). Diego and Christine 2015:363 further maintained that LSPs could play several roles in humanitarian logistics, ranging from that of service provider performing logistics operations, to full actors, sharing the design management and coordination of relief supply chain with non-profit organizations. Involving LPSs, such as, Third Party Logistics (3PL) tends to minimize the apparent bureaucracy occasioned by the use of government agencies in the distribution of relief materials at the various IDP camps in Nigeria.

Therefore, humanitarian Logistics is a business opportunity for LSPs that are willing to play prominent roles in humanitarian supply chain, depending on the degree of their interest (that is, from Corporate Social Responsibility (CSR) commitment in-form of in-kind donations, employees volunteering and so on, to Non-Governmental Organizations and government agencies, to the development of strategic business activities in relief logistics) (Diego and Christine 2015:367).

The figure 2 below shows the suggested distribution network for relief materials in Nigeria. 


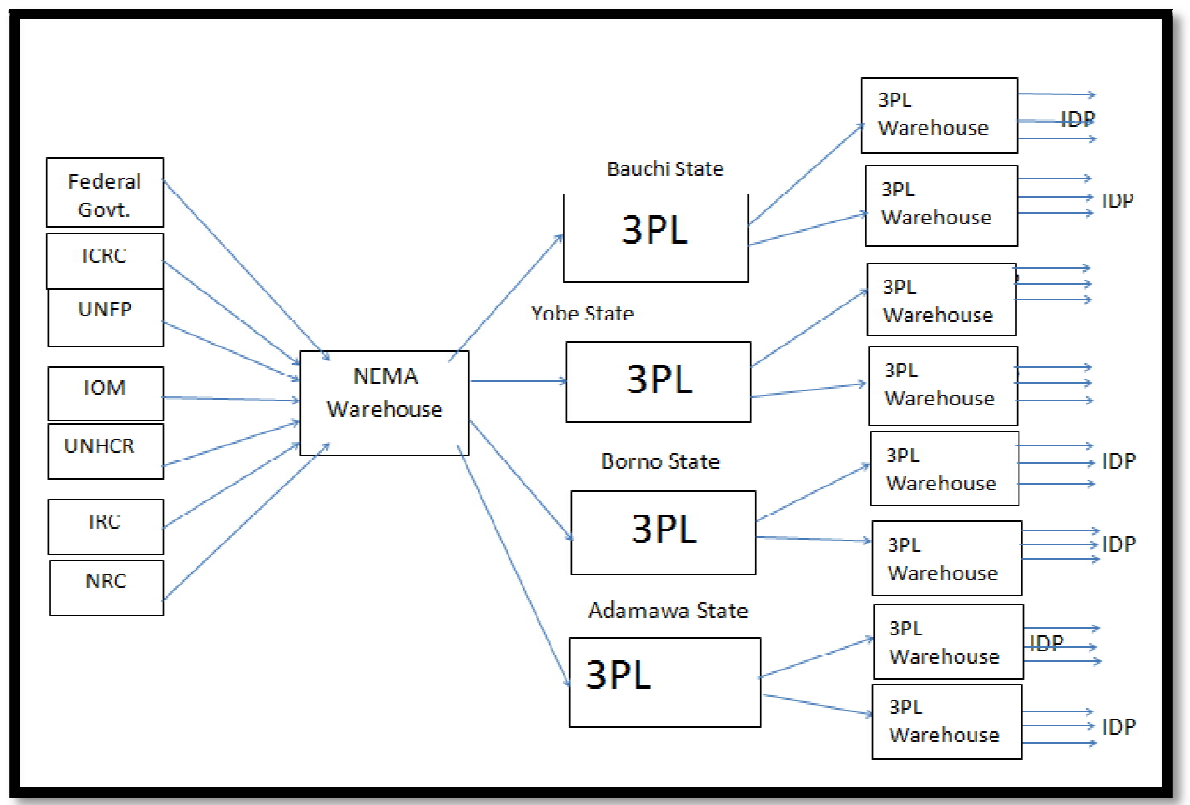

Figure 2: As - To - Be Distribution Network of Relief Materials in Nigeria Source: Designed by the Authors

\section{Conclusion and Recommendations}

The distribution network of relief materials in Nigeria is not effective. The Internally Displaced People (IDP) do not have adequate supply of relief materials despite the efforts of the federal government, as well as the various governmental and non-governmental agencies to ensure that they are well catered for. The factors responsible for this are, corruption, lack of a strong law backing the operations of the stakeholders, lack of clear-cut policies as well as operational guideline for the relief materials distribution and the bureaucracy involved in the operations of the relevant governmental agencies.

This study however, recommends that the National Emergency Management Framework (NDMF) in Nigeria should be signed into law to give proper operational guidelines and policies to all the agencies and authorities involved in the distribution of relief materials.

Moreover, the study further recommends the use of $3^{\text {rd }}$ Party Logistics (3PL) in the distribution operations of relief materials to the various IDP camps rather government agencies to minimize corruption and the bureaucracy involved in the distribution process.

\section{References}

i. Adewale, S. (2016). Internally Displaced Person and Challenges of Survival in Abuja. African Security Review, 25(2), Pg. 176-192.

ii. Amalu, N.S. (2015). Impact of Boko Haram Insurgency on Human Security in Nigeria. Global Journal of Social Sciences, 14, Pg.35-42

iii. Balcik, B. \& Beamon, B.M. (2008). Facility location in humanitarian relief. International Journal of Logistics Research and Application, 11(2), Pg.101-121.

iv. Balcik, B.; Beamon, B.M. \& Smitlowitz, K. (2008). Last mile distribution in humanitarian relief. Journal of Intelligent Transportation Systems, 12(2).

v. Blecken, A. (2010). Supply Chain Modeling for humanitarian organizations. International Journal of Physical Distribution\& Logistics Management, 40(89), Pg. 675-692.

vi. Bozorgi-Amiri, A.; Jabalameli, M.S.; Alinaghian, M. \& Heydari, M. (2012). A modified particle swarm optimization for disaster relief logistics under uncertain environment. International Journal of Advanced Manufacturing Technology, 60, Pg.357-371.

vii. Campbell, J. \& Harwood, A. (2018). Boko Haram Deadly Impact. Council on Foreign Relations, Available at:file:///C:/Users/MY\%20COMPUTER/Desktop/Boko\%20Haram\%20Insurgence\%206.htm, Accessed on

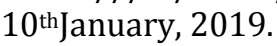

viii. Chopra, S. \& Sodhi, M.S. (2004). Managing Risk to Avoid Supply -chain Breakdown. MIT Sloan Management Review, Fall.

ix. Diego, V. \& Christine, R. (2015). Humanitarian Logistics: the role of service providers. International Journals of Physical Distributions \& Logistics Management, 45(4). Pg. 352-375.

x. Dufour, E.; Laporte, G.; Paquette, J. \& Rancourt., M. (2018). Logistics service network design for humanitarian response in East Africa. Omega, 74, Pg. 1-14.

xi. Dunn, G. (2018). The Impact of the Boko Haram insurgency in Northeast Nigeria on childhood wasting: a double Difference study. Dunn Conflict and Health, 126, Pg. 1-12.

xii. Fineman, G.G. (2018). Nigeria's Boko Haram and its Security Dynamics in the West African Sub Region. Journal of Language Technology \& Entrepreneurship in Africa, 9(1), Pg. 117. 
xiii. Fikar, C.; Gronalt, M. \& Hirsch, P. (2016). A decision support system for coordinated disaster relief distribution. Expert System with Applications, 57, Pg.104-116.

xiv. Gamawa, Y.I. (2017). Boko Haram Insurgency in Nigeria: Conflict, Peace building and Post Conflict Economic recovery. International Journal of Development and Sustainability, 6(7), Pg.451-466.

xv. GIFT OF THE GIVERS FOUNDATION (South Africa). Drought relief 2018: Project monthly report, February July, 2018.

xvi. Imasuen, E. (2015). Insurgence and Humanitarian Crisis in Northern Nigeria: The Case of Boko Haram. African Journal of Political Science and International Relations, 9(7), Pg.284-296.

xvii. INTERNATIONAL COMMITTEE OF RED CROSS, 2016: Internal Displacement in North East Nigeria: Operationalizing the Kampala Convention in Borno, Adamawa and Yobe States. A Report of Multidisciplinary Collaboration Between all ICRC Departments and Sub-structures Working in the North East of Nigeria, 2016: 154 (Available at: www.icrc.org, accessed on 10thJanuary, 2019).

xviii. Jahre, M. (2017). Humanitarian supply chain strategies - a review of how actors mitigate supply chain risks. Journal of Humanitarian Logistics and Supply Chain Management, 7(2), Pg.82-101.

xix. Kovacs, G. \& Spens, K. (2009). Identifying challenges in humanitarian logistics. International Journal of Physical Distribution \& Logistics Management, 39(6), Pg.506-528.

xx. Lins, L.C. (2009). An Integrated framework for the development of radio frequency identification technology in the logistics \& supply chain management. Computers and Industrial Engineering, 57, Pg.832-842.

xxi. Marianne, J. (2017). Humanitarian Supply Chain Strategies - a review of how actors mitigate supply chain risks. Journal of Humanitarian Logistics and Supply Chain Management, 7(2), Pg.82-101.

xxii. Mat Daud, M.S.; Hussein, M.Z.S.M.; Nasir, R.A; Kassim, R.; Suliman, M.S. \& Saludin, M.R. (2016). Humanitarian Logistics and Its Challenges: The Literature Review. International Journal of Supply Chain Management, 5(3), Pg.107-110.

xxiii. Muhammad, S.H.; Young, H.L. \& Muhammad, S.M. (2016). Mathematical models in Humanitarian Supply Chain Management: A Systematic Literature Review. Hindawi Publishing Corporation Mathematical Problems in Engineering, 1, Pg.1-20.

xxiv. Nagurney, A. \& Qiang, Q. (2012). Multiproduct humanitarian healthcare supply chains: a network modeling and computational framework. POMS. Annual

xxv. Conference (23rd:2012: Chicago, Illinois). (Available at: SSRN: https://ssrn.com/abstract=1636294 Accessed on August 2, 2018).

xxvi. NATIONAL EMERGENCY MANAGEMENT AGENCY (NEMA) (2010). National Disaster Management Framework. A Publication of NEMA, Abuja, Nigeria.

xxvii. Okoli, A.C. (2014). Disaster Management and National Security in Nigeria: The Nexus and the Disconnect. International Journal of Liberal Arts and Social Science, 2(1), Pg.21-59.

xxviii. Okwute, A. O; Sanda, A. \& Usman, M. (2017). Community Development In Emergency Situation: A Case Study of Internally Displaced Persons in Borno State. International Journal of Education and Research, 5(6), Pg.209-224.

xxix. Olanrewaju, F.O; Omotosho, F. \& Alabi, J.O. (2018). Datasets on the Challenges of forced displacement and coping strategies among displaced Women in selected Internally Displaced Persons' (IDPs) camps in Nigeria. Data Brief, 20, Pg.152-158

xxx. Ortuzar, J. D. D \& Willumsen, L. G.( 2011). Modelling Transport. Fourth Edition ed. London: John Wiley \& Sons, Ltd..

xxxi. Rodriguez-Espindola, O.; Albores, P. \& Brewster, C. (2018). Disaster preparedness in humanitarian logistics: A collaborative approach for resource management in floods. European Journal of Operational Research, 264, Pg.978-993.

xxxii. Rolando, M.T. \& Van Wassenhove, L.K. (2009). From preparedness to partnerships: case study research on humanitarian logistics. International Transactions in Operational Research, 6, January Pg. 459-559. Thomas, A.S.; \& Kopczak, R.L. (2005). From logistics to supply chain management: The path forward in the humanitarian sector, white paper.San Francisco, CA: The Fritz Institute

xxxiii. Tofighi, S; Torabi, S.A.\& Mansouri, S.A (2016). Humanitarian Logistics network design under mixed uncertainty. European Journal of Operational Research, 250(1), Pg.239-250. 